\title{
Role of Ambulatory Blood Pressure Monitoring in Postcoronary Intervention Patients
}

\author{
Jyotsna Maddury ${ }^{1}$ \\ ${ }^{1}$ Department of Cardiology, NIMS: Punjagutta, Hyderabad, \\ Telangana, India
}

Indian J Cardiovasc Dis Women-WINCARS 2018;3:1-1

Ambulatory blood pressure monitoring (ABPM) was done previously mainly to monitor the blood pressure (BP) control, for detection of white coat hypertension or masked hypertension and drug therapy adjustments. As BP variability is associated with increased cardiovascular events, ${ }^{1} \mathrm{ABPM}$ is used in many conditions like acute coronary syndromes, ${ }^{2}$ obstructive sleep apnea, ${ }^{3}$ chronic kidney disease, ${ }^{4}$ and risk of fall injury in elderly hypertensive patients ${ }^{5}$ for prognostication.

There are studies on the applicability of ABPM in postcoronary intervention also. ${ }^{6}$ According to Yang et al, percutaneous coronary intervention (PCI) causes improvement of BP indices, which can be picked up by ABPM. Tocci et al thought that ABPM may play a role in normotensive patients also after PCI. They showed that BP variability recorded on ABPM correlated with the subsequent stent restenosis. ${ }^{7}$

In this issue, Krishna et $\mathrm{al}^{8}$ studied the different BP parameters and indices derived by ABPM in post-PCI patients. Mainly they tested whether there was a difference in these ABPM parameters in between the males and females. Slightly more than one-fifth of the study population was females (21\%). Even though the authors mentioned consecutive patients were included in the study, $21 \%$ of females in the study population are not the correct reflection of the incidence of coronary artery disease (CAD) in women. This may be because less number of females undergoes $\mathrm{PCI}$ even now in contrast to the West where this disparity is decreasing.

Even though there were less percentage of female population in this study, this original article throws light on certain factors like in CAD patients undergoing $\mathrm{PCI}$, there was no difference in the ABP parameters between males and females and nondippers were more in both males ( 54.4 vs $45.6 \%$ ) and females ( 76.2 vs $23.8 \%$ ) when compared with the dippers. This higher incidence of nondippers on ABPM in both sexes requires special attention as these patients are likely to suffer from more cardiovascular events subsequently. ${ }^{9}$

\section{References}

1 Mehlum MH, Liestøl K, Kjeldsen SE, et al. Blood pressure variability and risk of cardiovascular events and death in patients with hypertension and different baseline risks. Eur Heart J 2018;39(24):2243-2251

2 Hassan AKM, Abd-El Rahman H, Mohsen K, Dimitry SR . Impact of in-hospital blood pressure variability on cardiovascular outcomes in patients with acute coronary syndrome. J Clin Hypertens (Greenwich) 2017;19(12):1252-1259

3 Rietz H, Franklin KA, Carlberg B, Sahlin C, Marklund M. Nocturnal blood pressure is reduced by a mandibular advancement device for sleep apnea in women: findings from secondary analyses of a randomized trial. J Am Heart Assoc 2018;7(13):pii: e008642

4 Angeli F, Gentile G, Trapasso M, Verdecchia P, Reboldi G. Role and prognostic value of individual ambulatory blood pressure components in chronic kidney disease. J Hum Hypertens 2018; 10.1038/s41371-018-0081-y

5 Jonas M, Kazarski R, Chernin G. Ambulatory blood-pressure monitoring, antihypertensive therapy and the risk of fall injuries in elderly hypertensive patients. J Geriatr Cardiol 2018;15(4):284-289

6 Yang J, Yang X, Liu W, Cao T. Effects of percutaneous coronary intervention on the ambulatory blood pressure of patients with hypertension and coronary heart disease. Ir J Med Sci 2015;184(4):845-850

7 Tocci G, Barbato E, Coluccia R, et al. Blood pressure levels at the time of percutaneous coronary revascularization and risk of coronary in-stent restenosis. Am J Hypertens 2016;29(4):509-518

8 Kenchi GK, Gajula S, Dangati MR. An observational study: ambulatory blood pressure monitoring after percutaneous transluminal coronary angioplasty. Ind J Car Dis Wom 2018;3(1):17-22

9 Salles GF, Reboldi G, Fagard RH, et al. for the ABC-H Investigators. Prognostic effect of the nocturnal blood pressure fall in hypertensive patients the ambulatory blood pressure collaboration in patients with hypertension $(\mathrm{ABC}-\mathrm{H})$ meta-analysis. Hypertension. 2016;67(4):693-700.

\section{Address for correspondence} Jyotsna Maddury, MD, DM, FACC, FESC, FICC, Department of Cardiology, NIMS: Punjagutta, Hyderabad, Telangana, India (e-mail: mail2jyotsna@ rediffmail.com).
DOI https://doi.org/ $10.1055 / \mathrm{s}-0038-1670100$.
Copyright $@ 2018$ Women in Cardiology and Related Sciences
License terms

() (1) $\Theta \circledast$ 